\title{
ON THE VALUE OF CONTINGENT ASSURANCES WITH CERTAIN LIMITATIONS.
}

To the Editor of the Assurance Magazine.

Sir, - Should you consider the accompanying solntions to the two following important problems worthy of a place in your Magazine, they are at your service.

You will observe that both of these problems have been previously solved by the late Mr. David Jones, in the first volume of his work on Annuities and Reversionary Payments, pages 140 and 184, but by processes very laborious, and resulting in formulæ totally unfit for practical use.

Mr. Peter Hardy has since solved the second problem, in the second volume of the Assurance Magazine, by a method equally if not more laborious than that above referred to; however, he possesses the claim of being the first who has put the result in a practical form.

This problem was last solved in a very elegant manner, without analysis, by your very able and talented correspondent Mr. T. B. Sprague, in the last number of your Magazine, after which it would be idle for me to attempt giving a more concise or elegant solution; but having some doubt as to whether the mode of investigation he has made use of is such as would occur to the student on first reading the problem, without having previously seen the analysis, I have been induced to send you the following general and brief analytical solutions to the two problems in question, thinking they may prove interesting to your actuarial readers.

I am, Sir,

$$
\text { Your obedient Servant, }
$$

\section{4, Trafalgar Square, w.o. WM. CURTIS OTTER, F.R.A.S.}

1st. Required the present value of an annuity payable during the joint lives of $\mathrm{A}$ and $\mathrm{B}$, aged respectively $m$ and $m_{1}$; and also during $t$ years after the death of $\mathrm{B}$, provided $\mathrm{A}$ lives so long.

The present value of the $n$th year's payment of this annuity depends upon the probability of $\mathrm{B}$ being alive at the end of the $n$th year, and $\mathrm{A}$ being alive at the end of the $\overline{n+t}$ th year,

$$
=p \cdot n_{1} \cdot n \cdot p_{m, \overline{n+t}}
$$

$\therefore$ the present value of the annuity

$$
\begin{aligned}
& =\underset{n=n}{n=0} \boldsymbol{r}^{n+t} \cdot p_{m n_{1} \cdot n} \cdot p_{m \cdot \overline{n+t}} \\
& =\Sigma r^{t} \cdot p_{m . t}+\Sigma r^{n+t} \cdot p_{m_{1}} p_{m n} \overline{n+t} \\
& =a_{(m)}+r^{t} p_{m . t} \Sigma r^{n} p_{m_{1} \cdot m+t . n} \\
& \left.=a_{n}-a_{(m)}\right\rceil_{t}+r^{t} \cdot p_{m . t} a_{3 n+t, m_{1}} \\
& =a_{n}-r^{t} \cdot p_{m, t}\left(a_{m+t}-a_{m+t . m_{1}}\right) \\
& =a_{m}-\frac{\mathrm{D}_{m+t}}{\mathrm{D}_{n}}\left(a_{m+t}-a_{m+t, m_{1}}\right) \text {, }
\end{aligned}
$$

the present value, sought in the most convenient form for practical use. 
2nd. Required the single and annual premium for the assurance of $£ 1$ payable on the death of $\mathrm{A}$, aged $m$, provided he die before $B$, aged $m_{1}$, or within tyears after the death of $\mathbf{B}$.

The present value of the $n$th year's payment of this assurance depends (1) upon the probability of A dying in the $(n+t)$ th year, and B being alive at the end of the $n$th year; (2) upon the probability of A dying in the $(n+t)$ th year and $\mathrm{B}$ dying in the $n$th year, restricted to the condition that they die at such periods of the year as shall make the interval between their deaths as near as possible $t$ years-

$$
\begin{aligned}
& \text { i.e., }\left(p_{n n . n+t-1}-p_{m . n+\ell}\right) p_{n_{1} . n}+\frac{1}{2}\left(p_{m, n+t-1}-p_{n, n+t}\right) \cdot\left(p_{m_{\mathrm{Y}} . n-1} p_{m_{\mathrm{1}}, n}\right) \\
& =\frac{1}{2}\left(p_{m, n+t-1}-p_{m, n+t}\right) \cdot\left(p_{m_{1}, n-1}+p_{m_{1}, n}\right) \\
& =\frac{1}{2} p_{m, t} \cdot\left(p_{m+t, n-1}-p_{m+t, n}\right) \cdot\left(p_{m_{1}, n-1}+p_{m_{1} \cdot n}\right) ;
\end{aligned}
$$

$\therefore$ the present value of the assurance

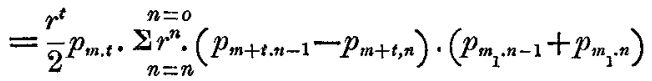

$$
\begin{aligned}
& =\mathrm{A}_{(m)}+\frac{r^{t} \cdot p_{m t}}{2} \Sigma r^{n} \cdot\left(p_{m+t, n-1}-p_{m+\ell n}\right) \cdot\left(p_{n_{1} \cdot n-1}+p_{m_{1} \cdot n}\right) \\
& =A_{(m)}{ }_{t\rceil}+r^{t} \cdot p_{m . t} \cdot A_{\frac{1}{m+t_{0}, n_{1}}} \\
& =\mathrm{A}_{m}-\mathrm{A}_{n+t} \cdot r^{t} \cdot p_{m t}+r^{t} p_{m t} \mathrm{~A} \frac{1}{m+t . m n_{1}} \\
& =\mathrm{A}_{m}-\frac{\mathrm{D}_{n+t}}{\mathrm{D}_{n}}\left(\mathrm{~A}_{m+t}-\mathrm{A}_{\frac{1}{m+t n_{1}}}\right) \text {, }
\end{aligned}
$$

the present value sought, being precisely the same result as given by Mr. Hardy in the second volume of the Assurance Magazine, p. 95, but which has here been arrived at by a much smaller amount of labour.

The annual premium must evidently be the last result divided by that of the first problem plus unity,

$$
=\frac{A_{n}-\frac{\mathrm{D}_{m+t}}{\mathrm{D}_{m}}\left(A_{n+t}-\mathrm{A}_{m+t m_{1}}\right)}{1+a_{n}-\frac{\mathrm{D}_{m+t}}{\mathrm{D}_{n}}\left(a_{n+t}-a_{m+t, m_{1}}\right)}
$$

Obs.-The reader will not fail to notice the striking similarity in the results of these two problems: the only difference being, the substitntion of the capital A for the italic a, or vice versa, subject to the modification of making the joint assurance, after substitution, a survivorship assurance, in accordance with the conditions of the second problem. This remarkable similarity would seem to suggest the idea that the solutions of all ordinary reversionary problems can be effected by solving the corresponding annuity problems, and simply changing the italic $a$ 's into capital A's: bearing in mind, in problems depending on a particular order of survivorship, to make the necessary modification, answering to the conditions of the problem as illustrated in the above solntions. How far my ideas on this point (which, I think, is worth consideration) are correct, I leave the reader to investigate. 